\title{
REVIEW
}

\section{Digestive Phenotypic Flexibility in Post-Metamorphic Amphibians: Studies on a Model Organism}

\author{
DANIEL E NAYA and FRANCISCO BOZINOVIC*
}

Center for Advanced Studies in Ecology \& Biodiversity, and Departamento de Ecología, Facultad de Ciencias Biológicas, Pontificia Universidad Católica de Chile, Santiago 6513677, Chile.

\begin{abstract}
Studies of phenotypic flexibility are central to the understanding of evolutionary and comparative physiology. Research conducted on many vertebrate species has shown that the digestive system is highly responsive and sensitive to environmental cues. However, amphibians, which are a standard and classic model organism for the study of many physiological processes, have been poorly considered in the study of ecological consequences on digestive flexibility. Here we review and analyze the current information on this topic for amphibians. We identify three major bodies of empirical evidence: a) seasonal changes in gut development, b) lack of dietary modulation of gut attributes in adult individuals, c) a relationship between feeding habits and the magnitude of digestive performance regulation. Once the natural history characteristics of the species under study are taken into account, all the evidence is in full agreement with the predictions of digestive theory. We propose that evolutionary and comparative physiology could benefit greatly from the study of phenotypic flexibility in amphibians.
\end{abstract}

Key terms: Amphibians, digestive theory, gut adjustments, phenotypic flexibility

\section{DIGESTIVE PHENOTYPIC FLEXIBILITY}

Within genetically uniform organisms, the capacity for change in response to different environmental conditions is known as phenotypic plasticity or phenotypic flexibility if these changes imply reversible transformations (Piersma \& Lindstrom, 1997; Piersma \& Drent, 2003). Animals continuously cope with environmental demands through behavioral, physiological, and structural changes that ensure appropriate function [(Overgaard et al., 2002; Palacios \& Bozinovic, 2003; Naya et al., 2003a;)]. It is usually hypothesized that these adjustments increase the biological performance of individuals (Huey \& Berrigan, 1996; Hammond \& Kristan, 2000).

The gastrointestinal tract represents a functional link between energy intake and energy allocation, and thus it has likely experienced many selective pressures during organic evolution (Secor, 2001). Over the last thirty years, phenotypic flexibility of the gut has been extensively investigated in many vertebrate species. These studies have made it clear that the digestive system is one of the most responsive and sensitive systems to environmental cues. Nevertheless, practically all of these studies were conducted on reptiles, birds, and small mammals (for reviews see Piersma \& Lindstrom, 1997; Starck, 1999; McWilliams \& Karasov, 2001).

The use of amphibians in the analysis of physiological problems predates the founding of modern physiology, and during the past century this group has become a standard for the study of several biological processes (Feder, 1992). From the perspective of digestive physiology, amphibians have some

\footnotetext{
* Corresponding Author: Francisco Bozinovic. Address: Center for Advanced Studies in Ecology \& Biodiversity and Departamento de Ecología, Facultad de Ciencias Biológicas, Pontificia Universidad Católica de Chile. Santiago 6513677, Chile, Telephone: (56-2)686-2618, Fax: (56-2)686-2621, E-mail: fbozinov@ bio.puc.cl
} 
characteristics that make them a highly interesting group for study, such as their adaptation to low energy flow (Pough, 1980). This characteristic determines their adaptive capacity for extensive regulation of gut performance, a trait also shared with reptiles (Secor, 2001). In addition, there are many practical reasons that make amphibians good organisms for physiological study. For example, many species are relatively abundant in the wild, easily captured and transported, easily maintained in the laboratory, and amenable to experimentation (Feder, 1992).

The aim of the present work is to critically review and analyze the current evidence and data on gut flexibility in amphibians within the theoretical framework of digestive theory (Sibly, 1981).

\section{EVIDENCE FOR AMPHIBIANS}

We have been conducting a bibliographic search through Web of Science and Biological Abstracts data bases since 1988. We use a three level nested design of keywords: digestive, intestinal and gut (first level), plasticity, flexibility, mass, enzyme/ $\mathrm{s}$ and transporter/s (second level), and amphibian/s (third level). We have also surveyed papers and general books about amphibians biology and physiology to obtain a more complete list of information.

Digestive flexibility was categorized as following observational and/or experimental approaches. Studies following the latter approach were further grouped according to the particular factors being evaluated. In addition, both observational and experimental studies were clustered according to the organizational level at which the digestive changes were analyzed (e.g. macroscopical, histological, molecular). Taking these groupings into account we summarized the retrieval information in Table I, which shows that there are three major bodies of evidence regarding amphibian digestive flexibility (see following sections). Most of the available evidence is based on experimental approaches, principally using Anuran species as animal models. There are two experimental studies that were not included in any of the major groupings. One of these studies reports an increase in digestive enzyme activity due to the effect of orally administered thyroxine in Bufo melanostictus (Bhattacharyya et al., 2002). The other study refers to the effects of evaporative water loss on overall gut water content (Churchill \& Storey, 1994).

\section{Seasonal changes in gut development}

In an early study, Juszczyk et al. (1966) analyzed seasonal variation in gut mass, as well as histology (i.e. stomach and intestine mucosa structure) in five age classes and both sexes of Rana temporaria. The main results of the study can be summarized as follows: a) individuals exhibit marked seasonal variation in gut development, correlated to the annual feeding cycle; b) during the period of high feeding activity female gut attains a much greater mass than male gut, c) the beginning of gut regression in the middle of terrestrial life (i.e. the active period) suggests endogenous control of gut changes. Based on this last paper, Naya et al. (2003b) evaluated seasonal variation in the intestinal length of the South American common frog (Leptodactylus ocellatus). Their results reinforced the existence of seasonal changes related to feeding and reproductive events, but also indicated a strong effect of sex. Indeed, the intestinal length flexibility in males appears to be coupled with the annual feeding cycle, while in females it is mainly connected to reproductive cycle. In addition, seasonal changes in gut length were more conspicuous for females than males.

Regarding adjustments of the digestive tract during hibernation, Geuze (1971a, b) described the histological and ultrastructural changes that occur in the gastric mucosa of Rana esculenta, reporting a marked decrease in the digestive mucosa development during winter. The fact that mucosa activation begins before the end of hibernation provides new evidence for endogenous control of digestive changes. Recently, Goslling et al. (1982a, b) analyzed the flexibility of the large intestine bacterial flora during hibernation in $R$. pipens. These authors experimented with natural and lab induced hibernation and found a decrease in bacterial abundance as well as a change in the composition of the bacterial flora 
(Goslling et al., 1982a). These results suggest that a decrease in environmental temperature, rather than the absence of food, is the main factor explaining observed changes (Goslling et al., 1982b).

\section{Hard-wired digestive physiology in adults}

In two back-to-back papers, Toloza \& Diamond (1990a, b) evaluated the ontogenetic changes in brush border transporters and intestinal morphometry for $R$. catesbeiana; then they analyzed the flexibility of these traits under different dietary treatments. These authors found that pre-metamorphic individuals exhibited the capacity for rapid, reversible modifications (i.e. dietary modulation), which is lost during adulthood. Five years later, Sabat \& Bozinovic (1996), used this result to formulate the hypothesis of 'digestive physiological rigidity in adult amphibians' (i.e. hard-wired physiology), which they tested using Bufo spinulosus. The digestive variables measured in this case were the activity of three digestive enzymes, the disacharidases sucrase, maltase and trehalase. As in $R$. catesbeiana, adult individuals of $B$. spinulosus were unable to modulate their digestive enzyme activities in response to dietary chemical composition.

\section{Feeding habits and the regulation of digestive performance}

Probably the most interesting result regarding digestive flexibility in amphibians is the digestive changes that follow an alimentary event in species that feed infrequently. Secor (2001) analyzed differences in the factorial increase of intestinal uptake capacity of aminoacids and sugars (L-proline, L-leucine and D-glucose), for seven species of frequent feeders and two species of infrequent feeders (see Table I). Clearly, the latter two species down-regulated gut performance following digestion, whereas the frequently feeding species constantly maintained a fully functional gut. These results are highly congruent with current data for other ectotherms (see Secor \& Diamond, 2000; Secor, 2001), suggesting that amphibians may represent another important model for a complete understanding of digestive phenotypic flexibility (see Secor \& Diamond, 1998).

\section{DISCUSSION}

Studies of phenotypic flexibility are central to the understanding of evolutionary and comparative physiology (Huey \& Berrigan, 1996; Hammond \& Kristan, 2000). Research on gut flexibility in amphibians is very scarce, and several studies have not been published in peer-reviewed journals. Interestingly, reported data are congruent and consistent, and, more importantly, they support the general theoretical framework of gut phenotypic flexibility (e.g. Sibly, 1981; Penry \& Jumars, 1987; Martínez del Río et al., 1994). In this sense, it is interesting to note that some of the results reported by Juszczyk and collaborators nearly four decades ago still comprise central ideas about digestive regulation.

What are the predictions of the digestive physiology theory for amphibians and what empirical evidence exists? Our survey indicated that there are three different bodies of evidence regarding gut flexibility in amphibians, and each one should be interpreted in the light of the digestive theory and species natural history. First, amphibian species living in temperate regions likely face strong seasonal variation in abiotic and biotic factors; therefore theory predicts seasonal variations in gut development (Larsen, 1992). Results supporting this idea are presented in the first section of "Evidence for amphibians." Second, since food composition in post-metamorphic anurans only varies slightly, theory predicts a lack of dietary modulation of gut changes in adult individuals. Data that sustain this hypothesis are given in the second section of "Evidence for amphibian." Third, many amphibian species are able to fast for several months in the wild. For these infrequent feeder species, theory expects a wide regulation of gut performance. Evidence of a correlation between feeding frequency and the magnitude by which digestive performance is regulated is reported in the third section of "Evidence for amphibians." 


\section{TABLE I}

Studies of gut flexibility in amphibians reviewed in this communication. Obs $=$ observations made in the field, Exp $=$ Experimental manipulations, Mass $=$ gut dry mass,

Length $=$ lineal gut length, Area $=$ nominal gut area, Histology $=$ digestive mucosa histology, Ultrastructure $=$ digestive mucosa ultrastructure, Bacterial flora $=$ amount and composition of intestinal bacterial flora, Transporters = digestive brush-boarder transporters, Enzymes = digestive enzymes, Water content = gut water content. All species are Anurans, except those species marked with an asterisk, which belong to the order Urodela.

\section{Seasonal changes in gut development}

\begin{tabular}{lcccc}
\hline Species & Approaches & Experimental Factors & Organizational Level & Source \\
\hline $\begin{array}{l}\text { Rana temporaria } \\
\text { Leptodactylus ocellatus }\end{array}$ & Obs & & Mass, Histology & Juszczyk et al., 1966 \\
$\begin{array}{l}\text { Rana pipens } \\
\text { Rana pipens }\end{array}$ & Obs / Exp & Temperature & Length & Naya et al., 2003b \\
Rana esculenta & Exp & $\begin{array}{c}\text { Temperature, } \\
\text { Feeding frequency }\end{array}$ & Bacterial flora & Goslling et al., 1982a \\
& Exp & Temperature & Histology, & Geuze, 1971a, b \\
\end{tabular}

\section{Hard-wired physiology of adults}

\begin{tabular}{lcccc}
\hline Species & Approaches & Experimental Factors & Organizational Level & Source \\
\hline Rana catesbiana & Exp & Diet composition & $\begin{array}{c}\text { Mass, Length, } \\
\text { Area, Transporters }\end{array}$ & $\begin{array}{l}\text { Toloza \& Diamond, } \\
1990 \mathrm{a}, \mathrm{b}\end{array}$ \\
Bufo spinulosus & Exp & Diet composition & Enzymes & $\begin{array}{l}\text { Sabat \& } \\
\text { Bozinovic, } 1996\end{array}$ \\
\hline
\end{tabular}

\section{Feeding habits and digestive regulation ${ }^{1}$}

\begin{tabular}{lcccc}
\hline Species & Approaches & Experimental Factors & Organizational Level & Source \\
\hline Rana catesbieiana & Exp & Feeding frequency & Transporters & Secor, 2001 \\
Rana pipens & Exp & Feeding frequency & Transporters & Secor, 2001 \\
Hyla regilla & Exp & Feeding frequency & Transporters & Secor, 2001 \\
Hyla cadaverina & Exp & Feeding frequency & Transporters & Secor, 2001 \\
Bufo marinus & Exp & Feeding frequency & Transporters & Secor, 2001 \\
Ceratophrys ornate $_{\text {Pyxicaphalus adspersus }}$ & Exp & Feeding frequency & Transporters & Secor, 2001 \\
Tarchica granulose* & Exp & Feeding frequency & Transporters & Secor, 2001 \\
Tarchica torosa & Exp & Feeding frequency & Transporters & Secor, 2001 \\
\hline
\end{tabular}

\section{Other studies}

\begin{tabular}{lcccc}
\hline Species & Approaches & Experimental Factors & Organizational Level & Source \\
\hline Bufo melanostictus & Exp & Thyroxine doses & Enzymes & Bhattacharyya et al., \\
Psuedacris crucifer & Exp & Dehydration & Water content & $\begin{array}{l}\text { Churchill \& } \\
\text { Storey, } 1994\end{array}$ \\
\hline
\end{tabular}

\footnotetext{
${ }^{1}$ Note that this idea was originally proposed in an abstract of the 1996 Annual Meeting of the Society for Integrative and Comparative Biology, in which the authors give data on digestive transporters and enzymes, and intestinal masses of three anuran species (Secor and Diamond, 1996).
} 
We would like to propose some directions for further research on this topic. 1) The idea that seasonal changes of amphibian gut are under endogenous control mainly comes from circumstantial evidence from field studies. Experiments that would allow researchers to separate natural conditions from experimental conditions are needed to validate this hypothesis. 2) There is much evidence supporting the idea that flexibility in digestive function could result from a sequence of progressive adjustments to face increasing energy demands (e.g. Derting \& Bogue, 1993; Nagy \& Negus, 1993; Yang \& Joern, 1994). To test this idea in amphibians, we propose conducting experiments that evaluate digestive changes at more than one organizational level, and over an energy demand gradient. 3) Although the diversity in trophic habits among adult amphibians is low, testing the effect of some specific dietary chemical compounds on digestive dynamic could prove to be promising. For example, it would be interesting to know whether chitin plays a similar role to that observed for dietary fibers in herbivorous vertebrates. 4) Recent work has challenged the energetic model, which predicts a correlation between gut flexibility and feeding regime (see Strarck \& Beese, 2001; Overgaard et al., 2002); some amphibian species could be excellent models for evaluating the relationship between the energetic cost of a meal and the time elapsed between two feeding events.

The vertebrate class Amphibia exhibits extraordinary biological diversity and evolutionary novelty, having persisted through eons of environmental challenges (Feder, 1992). The recent recognition of different phenomenon related to amphibian ecology, such as their pivotal role in aquatic communities (Duellman \& Trueb, 1994; Stebbins \& Cohen, 1995) and the global decline in their populations (Wake, 1991; Alford \& Richards, 1999), has elevated the research interest in this taxonomic group. Here we similarly propose that evolutionary and comparative physiology could greatly benefit from the study of phenotypic flexibility in amphibians.

\section{ACKNOWLEDGMENTS}

DEN acknowledges the 'BBB Research Group' members in Uruguay for fruitful discussions on amphibian biology, and a Ph.D. fellowship from DIPUC/ P. Universidad Católica de Chile and Comisión Nacional de Investigación Científica y Tecnológica (CONICYT, Chile). Funding by the Center for Advanced Studies in Ecology \& Biodiversity (CASEB, Program 1) to FB. This paper is dedicated to the memory of Francisco Bozinovic Rajcevic.

\section{REFERENCES}

ALFORD RA, RICHARDS SJ (1999) Global amphibian declines: a problem in applied ecology. Ann Rev Ecol Syst 30: $133-165$

BHATTACHARYYA SK, CAKI KK, MISRA KK (2002) Effect of thyroxine on some diegestive enzymes of the adult male toad, Bufo melanostictus. Folia Biologica (Krakow) 50: 83-90

CHURCHILL TA, STOREY KB (1994) Effects of dehydration on organ metabolism in the frog Pseudacris crucifer -hyperglycemic response to dehydration mimic freezing-induced cryoportectant production. J Comp Physiol B 164: 492-498

DERTING TL, BOGUE BA (1993) Responses of the gut to moderate energy demands in a small herbivore (Microtus pennsylvanicus). J Mammal 74: 59-68

DUELLMAN WE, TRUEB L (1994) Biology of Amphibians. Baltimore: Johns Hopkins University Press

FEDER ME (1992) A perspective on environmental physiology of the Amphibians. In: FEDER ME, BURGGREN (eds) Environmental Physiology of the Amphibians. Chicago and London: University of Chicago Press. pp: 1-6

GEUZE JJ (1971a) Light and electron microscope observations on the gastric mucosa of the frog (Rana esculenta): I. Normal structure. Z Zellforsc 117: 87-102

GEUZE JJ (1971b) Light and electron microscope observations on the gastric mucosa of the frog (Rana esculenta): II. Structural alternations during hibernation. Z Zellforsc 117: 103-117

GOSLLING J, LOESCHE WJ, NACE GW (1982a) Large intestine bacterial flora of nonhibernating and hibernating leopard frogs (Rana pipens). Appl Environ Microbiol 44: 59-66

GOSLLING J, LOESCHE WJ, NACE GW (1982b) Response of intestinal flora of laboratory-reared leopard frogs (Rana pipens) to cold and fasting. Appl Environ Microbiol 44: 67-71

HAMMOND KA, KRISTAN DM (2000) Responses to lactation and cold exposure by deer mice (Peromyscus maniculatus). Physiol Biochem Zool 73: 547-556

HUEY RB, BERRIGAN D (1996) Testing evolutionary hypotheses of acclimation. In: JOHNSTON IA, BENNETT AF (eds) Animals and temperature. Phenotypic and evolutionary adaptation. Cambridge: Cambridge University Press. pp: 205-23

JUSZCZYK W, OBRZUT K, ZAMACHOWSKI W (1966) Morphological changes in the alimentary canal of the 
common frog (Rana temporaria L.) in the annual cycle. Acta Biol Cracov (Zool) IX: 239-246

LARSEN LO (1992) Feeding and Digestion. In: FEDER ME, BURGGREN (eds) Environmental Physiology of the Amphibians. Chicago and London: University of Chicago Press. pp: 378-394

MARTÍNEZ DEL RÍO C, CORK SJ, KARASOV WH (1994) Modelling gut function: an introduction. In: CHIVER J, LANGER P (eds) The digestive system in mammals. Cambridge: Cambridge University Press. pp: 25-53

MCWILLIAMS SR, KARASOV WH (2001) Phenotypic flexibility in digestive system structure and function in migratory birds and its ecological significance. Comp Biochem Physiol A 128: 579-593.

NAGY TR, NEGUS NC (1993) Energy acquisition and allocation in male collared lemmings (Dicrostonyx groenlandicus): effects of photoperiod, temperature, and diet quality. Physiol Zool 66: 537-560

NAYA DE, BACIGALUPE LD, BUSTAMANTE DM, BOZINOVIC F (2003a) Estrategias digestivas dinámicas en respuesta al incremento en la demanda energética en Phyllotis darwini. Biol Res 36: R21

NAYA DE, MANEYRO R, CAMARGO A, DA ROSA I, CANAVERO A (2003b) Annual changes in gut length of South American common frog (Leptodactylus ocellatus). Biociencias 11: 47-52

OVERGAARD J, ANDERSEN JB, WANG T (2002) The effects of fasting duration on the metabolic response to feeding in Python molurus: an evaluation of the energetic costs associated with gastrointestinal growth and upregulation. Physiol Biochem Zool 75: 360-368

PALACIOS AG, BOZINOVIC F (2003) An "enactive" approach to integrative and comparative biology: Thoughts on the table. Biol Res 36: 101-105

PENRY DL, JUMARS PA (1987) Modeling animal guts as chemical reactors. Am Nat 129: 69-96

PIERSMA T, DRENT J (2003) Phenotypic flexibility and the evolution of organismal design. Trends Ecol Evol 18: $228-233$

PIERSMA T, LINDSTROM, A (1997) Rapid reversible changes in organ size as a component of adaptative behaviour. Trends Ecol Evol 12: 134-138
POUGH FH (1980) Amphibians and reptiles as low-energy systems. In: WAYNE PA, LUSTICK SI (eds) Behavioral Energetics: the Cost of Survival in Vertebrates. Columbus: Ohio State University Press. pp: $141-188$

SABAT P, BOZINOVIC F (1996) Dietary chemistry and allometry of intestinal disaccharidases in the toad Bufo spinulosus. Rev Chil Hist Nat 69: 387-391

SECOR SM (2001) Regulation of digestive performance: a proposed adaptive response. Comp Biochem Physiol A 128: 565-577

SECOR SM, DIAMOND JM (1996) Adaptive responses of digestive physiology in frogs. Am Zool 36: $17 \mathrm{~A}$

SECOR SM, DIAMOND JM (1998) A vertebrate model of extreme physiological regulation. Nature 395: 659-662

SECOR SM, DIAMOND JM (2000) Evolution of regulatory responses to feeding in snakes. Physiol Biochem Zool 73: 123-141

SIBLY RM (1981) Strategies of digestion and defecation In: TOWSEND CR, CALOW P (eds) Physiological Ecology: an Evolutionary Approach to Resource Use. Oxford: Blackwell Scientific Publications. pp: 109-139

STARCK (1999) Structural flexibility of the gastrointestinal tract of vertebrates - implications for evolutionary morphology. Zool Anz 238: 87-101

STARCK JM, BEESE K (2001) Structural flexibility of the intestine of Burmese python in response to feeding. J Exp Biol 204: 325-335

STEBBINS RC, COHEN NW (1995) A Natural History of Amphibians. New Jersey: Princeton University Press

TOLOZA EM, DIAMOND JM (1990a) Ontogenetic development of transporters regulation in bullfrog intestine. Am J Physiol 258: G760-G769

TOLOZA EM, DIAMOND JM (1990b) Ontogenetic development of transporters regulation in bullfrog intestine. Am J Physiol 258: G770-G773

WAKE DB (1991) Declining Amphibian Populations. Science 253: 860

YANG Y, JOERN A (1994) Influence of diet quality, developmental stage and temperature on food residence time in Melanoplus differentialis. Physiol Zool 67: 598-616 